\title{
Material Selection Techniques for Polymer Hubs of Novel Spinal Stem Cell Introducers using Finite Element and Weighted Property Method
}

\author{
Muhammad Irsyad ${ }^{1}$, Muhammad Hanif Nadhif ${ }^{1,2^{*}}$, Ahmad Jabir Rahyussalim ${ }^{3 * *}$, Hanif \\ Assyarify ${ }^{1}$, Muhammad Satrio Utomo ${ }^{1,2,4}$

\begin{abstract}
${ }^{1}$ Medical Technology Cluster, Institute of Medical Education and Research Indonesia (IMERI), Faculty of Medicine, Universitas Indonesia, JL. Salemba Raya No.6, Jakarta 10340, Indonesia

${ }^{2}$ Department of Medical Physics, Faculty of Medicine, Universitas Indonesia, JL. Salemba Raya No.6, Jakarta 10340, Indonesia

${ }^{3}$ Deparment of Orthopedics and Traumatology, Faculty of Medicine/Ciptomangunkusumo Central Hospital, Universitas Indonesia, Jakarta 10430, Indonesia

${ }^{4}$ Research Center for Metallurgy and Material, Indonesia Institute of Science (LIPI), Banten 15310, Indonesia
\end{abstract}

\begin{abstract}
Stem cell studies have progressed significantly in the last decades. Similarly, stem cell therapies have also been applied in clinical settings, includingthe spine. However, stem cells' delivery to the spinal region requires delicate procedures, demanding reliable introducers in addition to the surgeons' psychomotor skills. The introducer is a tubular sleeve to guide a syringe needle to deliver and draw fluids into and from the body, respectively. To date, there is no introducer dedicated to spinal stem cell deliveries. Our group proposed a dedicated introducer for spinal stem cell therapies, which consists of a needle and a hub (a base part of an introducer for gripping and handling). We focused onthe weighting property method (WPM) to select four polymer candidates for the hub:polystyrene, polycarbonate, polypropylene, and polyethylene. Prior to WPM, the mechanical integrity of the hub candidates was analyzed using the finite element method to determine the von Mises Stress (vMS) values. Accordingly, the vMS for each case and the material was compared with the respective tensile strength (TS), thereby vMS:TS ratio (MTR).MTR was included as one of the properties in WPM, in addition to prices, critical radiation doses, hardness, water absorption, and isopropyl alcohol resistance.According to the WPM calculation, polycarbonate received the highest score, thereby recommended for further introducer fabrications.
\end{abstract}

Keywords: Finite element method introducer; Polymer; Spine; Weighting property method

\section{Introduction}

Stem cells are currently used extensively in many fields, including medicine. Reportedly, human embryonic stem cell-derived cardiac progenitors were used for severe heart failure treatment in a clinical case (Menasché et al., 2015). The mesenchymal stem cell (MSC), the most studied cell product, was also used for the treatment of many lung diseases, such as chronic obstructive pulmonary disease, acute respiratory distress syndrome, and idiopathic pulmonary fibrosis (Geiger et al., 2017). Moreover, due to the

${ }^{*}$ Corresponding author's email: hanifnadhif@ui.ac.id, rahyussalim71@ui.ac.id, Tel.: +62-21-3155576

${ }^{* *}$ Co-first authors; contributed equally to this work

doi: 10.14716/ijtech.v11i5.4320 
development of regenerative medicine, stem cell transplantation has become a promising method for spinal diseases and injuries. Several in vivo studies and clinical trials demonstrated that using stem cells as a therapeutic tool induced improvement of motor functions and neurological conditions (Silvestro et al., 2020).

Stem cell therapies at the spinal cord include spine fusions, disc degenerations, and spinal cord injuries. MSCs from bone marrows, adipose tissues, periosteum, and skeletal muscles could differentiate into osteoblasts. Genetically modified MSCs reportedly induced spinal fusion in mice through BMP-2 expression, a growth factor related to spinal fusion. The degenerative disc disease is a result of an alteration in the biochemical composition, which affects the morphological condition of the spinal disc. The potential of MSCs to differentiate into various cell lineages was utilized by researchers to build chondrocyte-like cells expressing the nucleus pulposus-like phenotype (Schroeder et al., 2015). In several studies, the use of bone marrow MSCs on subjects with spinal cord injury showed improved motor functions and quality of life (Silvestro et al., 2020).

There are two current methods to deliver stem cells into the spinal cord: systemic and direct delivery methods. The systemic delivery methods consist of intravascular and intrathecal infusion, while the direct delivery method is performed by direct intraparenchymal injection. The systemic delivery methods require stem cells to migrate to the pathological areas, unlike the direct delivery method. The direct intraparenchymal injection requires laminectomy and opening of the duramater, which are usually performed without any stabilization. This method is considered high-risk due to several factors, such as the unreliable targeting to the spinal cord, the unsteady needle that can move and break the white matter tracts, and the uncontrolled injection rate that might promote reflux due to the elevated intraparenchymal pressure. However, direct injection is preferred for stem cell deliveries because it was more accurate and had a high success rate of cell engraftment. The advanced injection system could also be improved by advanced imaging-guided techniques, such as the integration with magnetic resonance imaging (MRI) to improve the targeting capability and reduce procedural errors. To enhance the efficacy of this method, the existing injection devices should be modified appropriately to make them compatible with the MRI (Donnelly et al., 2012).

To perform this method, using an introducer to guide a syringe needle to deliver and draw the stem cells was needed. However, there is no existing introducer dedicated to spinal stem cell delivery. The existing introducers for spinal therapies are mainly for anesthesia. Our group proposed a dedicated introducer for spinal stem cell therapies, which consists of a needle and a hub (a base part of an introducer for gripping and handling). As the needle dimensions are standardized, we focused on the weighting property method (WPM) to select four polymer candidates for the hub: polystyrene (PS), polycarbonate (PC), polypropylene (PP), and polyethylene (PE). Prior to WPM, the mechanical integrity of the hub candidates was analyzed using the finite element method (FEM) to determine the von Mises Stress (vMS) values. Accordingly, the vMS for each case and the material was compared with the respective tensile strength (TS), thereby vMS:TS ratio (MTR). MTR was included as one of the properties in WPM, in addition to prices, critical radiation doses (CRD), hardness, water absorption (WA), and isopropyl alcohol (IPA) resistance. 


\section{Methods}

\subsection{Design Consideration}

The design consideration was based on the following parameters: needle size, needle length, bevel angle, needle material, and hub material. The size and length of introducers vary depending on the target, insertion location, and user. For instance, the 18 Gauge was used by less experienced operators because the diameter was bigger (Derby et al., 2016). Meanwhile, the length of the introducer was 3.5inch (Derby et al., 2016). The $27^{\circ}$ bevel angle of the introducer tip used to decrease the deflection result from inserting the needle into the skin tissue (Jushiddi et al., 2019). Stainless steel alloys have been used in the orthopedic implant (Jujur et al., 2015; Saini et al., 2015) and medical equipment (Tsen and Hepner, 2006; Bakar Sulong et al., 2016). In this study, AISI-grade-304 stainless steel (SS304) was used as the material due to its superior resistance to corrosion (Black et al., 2017), and it has been extensively implemented as hypodermic needles and surgical equipment (Lingadurai et al., 2012). Regarding the hub, four distinct types of the hub were found: PS, polycarbonate (PC), PP, and PE (Mcwha, 1998). Accordingly, we designed the novel spinal stem cell introducers; the needles are made of SS 304 and the hubs are made of the four polymer candidates. As the introduction stated, the introducers with different hub candidates were investigated using FEM so that the resulted vMS can be used as one of the properties in WPM.

\subsection{FEM}

A COMSOL Multiphysics 4.5 simulation software to perform the FEM. The mechanical integrity of the models was evaluated using a solid mechanics module in the stationary study. Previously, the model was designed using an Autodesk Inventor Professional 2020 modeling software. The introducer model consists of the hub part and the needle part. Those parts were assembled in Autodesk Inventor, as presented in Figure 1. Subsequently, the models were transferred to COMSOL using a Livelink feature, which converted and exported the specified geometry model of Autodesk Inventor to a COMSOL-type geometry. The model was formed as a union because the hub and the needle were assumed to have perfect bonding. In this study, the linear elastic material of the solid model was set as isotropic for both the hub and the needle. The parameters of each material, including the mechanical properties, are defined in Table 1 . The polymer material parameters referred to materials overview of the MatWeb database (MatWeb, 2020), except for the Poisson ratio.

Table 1 Mechanical properties of the introducer materials, extracted from Thomas et al. (2008); Yang et al. (2011); Khalajmasoumi et al. (2012); Lingadurai et al. (2012); Faiz et al. (2017)

\begin{tabular}{lcccc}
\hline \multicolumn{1}{c}{ Material } & $\begin{array}{c}\text { Elastic Modulus } \\
(\mathrm{GPa})\end{array}$ & $\begin{array}{c}\text { Tensile Strength } \\
(\mathrm{MPa})\end{array}$ & $\begin{array}{c}\text { Density } \\
\left(\mathrm{kg} / \mathrm{m}^{3}\right)\end{array}$ & Poisson's Ratio \\
\hline AISI SS304 & 193 & 515 & 8000 & 0.3 \\
Polystyrene (PS) & 3.48 & 47.8 & 836 & 0.33 \\
Polycarbonate (PC) & 2.38 & 64 & 1200 & 0.35 \\
Polypropylene (PP) & 1.70 & 29.8 & 930 & 0.392 \\
Polyethylene (PE) & 0.97 & 21.6 & 954 & 0.374 \\
\hline
\end{tabular}

Mechanical integrity tests for each model were performed under various cases: (1) compressive stress on the base of the introducer hub; (2) compressive stress on the tip of 
the introducer needle; and (3) grip force on the two sides of the introducer hub (illustrated in Figure 1). In the first case, the hub base was defined as a boundary load because the compressive stress was applied on the base surface. Meanwhile, the needle tip was defined as a fixed constraint. On the contrary, the boundary load and the fixed constraint were flipped in the second case. The compressive stress was set at 300 psi $(2068.43 \mathrm{kPa})$, assuming the force when the introducer falls to the ground. For the grip force, the two sides of the introducer hub were defined as boundary loads and the needle tip as a fixed constraint. Based on the literature in the field of microsurgery, the required force to grip a needle is at least $4 \mathrm{~N}$ (Sallé et al., 2004). Assuming that the grip force can be multiplied 5fold of the minimal force when maintaining the needle position, the pressure work on the two sides of the grip can reach $20 \mathrm{~N}$. Considering the safety factor of 4, the force used in this study became $80 \mathrm{~N}$. The model mesh was based on the COMSOL default setting and the element size was set as Finer. The FEM outputs resulted in von Mises stress (vMS) of each hub material and test case. The vMS of the first, second, and third case was labeled with vMS-1, vMS-2, and vMS-3, respectively. Following is the vMS equation (Equation 1):

$$
\sigma_{V}=\sqrt{\frac{\left(\sigma_{11}-\sigma_{22}\right)^{2}+\left(\sigma_{22}-\sigma_{33}\right)^{2}+\left(\sigma_{11}-\sigma_{33}\right)^{2}+6\left(\sigma_{12}^{2}+\sigma_{13}^{2}+\sigma_{23}^{2}\right)}{2}}
$$

where $\sigma_{v}$ is the stress on a respective part of the plane in the spinal introducer. The highest and lowest values of the vMS distribution were visualized using a color scale.

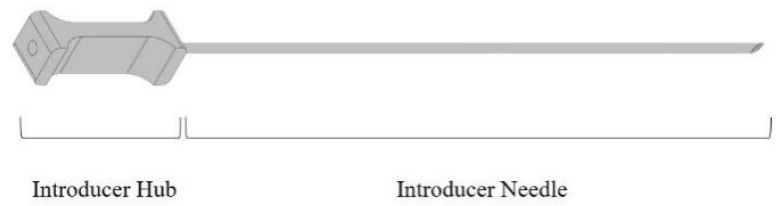

(a)

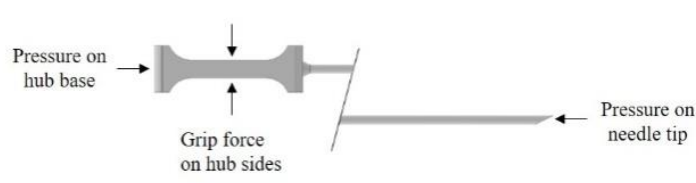

(b)

Figure 1 Computer-aided design (CAD) of the spinal stem cell introducer (a) and the force directions working on the introducer (front view of the model) (b)

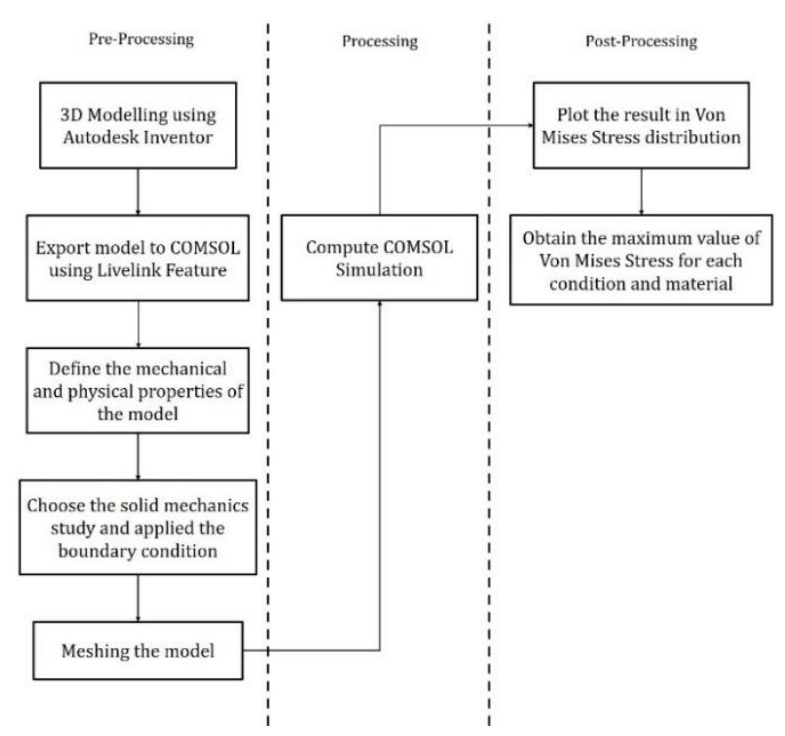

Figure 2 Finite element method scheme 


\subsection{Weighted Property Method (WPM)}

In this study, the WPM calculation was based on Farag (2013), and each material property is given a certain weight, depending on its importance. A weighted property value was attained by multiplying the property's numerical value by the weighting factor $(\alpha)$. The individual weighted property values of each material were subsequently summarized to give a comparative material performance index $(\gamma)$. Materials with higher performance index $(\gamma)$ were considered more suitable for the application.

The weighting factor was determined using the Digital Logic (DL) method. In the DL method, two properties were compared head-to-head following the single round-robin tournament. No shades of the result were required, only yes (more important $=1$ ) and no (less important $=0$ ) decisions for each comparison. A table was constructed to determine the relative importance of each property. The properties were listed in the left-hand column and comparisons were made along with the columns to the right, as shown in Table 2 . The $\alpha$ for each property can be calculated as (Equation 2)

$$
\alpha=m / N
$$

where $m$ is the positive decision for each property, and $N$ is the total number of possible decisions.

Each property of candidate material was scaled to ensure that the highest numerical value did not exceed 100 . When evaluating a list of candidate materials, one property was considered at a time. The best value in the list was rated as 100 and the others were scaled proportionally. For a given property, the scaled value $(\beta)$ for a given candidate material was equal to (Equation 3)

$$
\beta=\frac{\text { Numerical value of property } \times 100}{\text { Maximum value in the list }}
$$

On the contrary, when the lower value of a property is more desirable, such as the price, WA, and IPA resistance, the lowest value of $\beta$ was rated as $100 . \beta$ was calculated as (Equation 4)

$$
\beta=\frac{\text { Minimum value in the list } \times 100}{\text { Numerical value of property }}
$$

For a property like IPA resistance, numerical values are rarely given. Materials are commonly rated as good, fair, poor, and others. In such cases, the rating can be converted to numerical values using a relative scale (Farag, 2013). After scaling the different properties, the $\gamma$ can be calculated as (Equation 5)

$$
\gamma=\sum_{i=1}^{n} \beta_{i} \alpha_{i}
$$

where $i$ is summed over all the $n$ relevant properties.

As mentioned in the introduction, MTR was included as one of the properties in WPM. However, the FEM procedure resulted in three MTR values, following the vMS result from three distinctive cases, hence MTR-1, MTR-2, and MTR-3. The MTR can be calculated as (Equation 6)

$$
M T R=(v M S / T S) \times 100 \%
$$

where vMs was the value obtained using FEM for each case and material, TS was the tensile strength of each material obtained from Table 1 . As a result, there were eight distinctive properties: MTR-1, MTR-2, MTR-3, hardness, CRD, WA, and IPA resistance. 


\section{Results and Discussion}

The COMSOL post-processing feature was used to extract the vMS values of each hub material and test case so that the mechanical integrity of the model could be determined. As the materials of the hub and needle were different, the vMS values were evaluated separately. The stress distribution depended on the location and direction of the applied force. As mentioned in the method, there were three cases used to determine the mechanical integrity of the model (illustrated in Figure 1). In the first case, for the hub and the needle, the resulted vMS peaked at the hub part in contact with the base of the needle and the tip of the needle, respectively. The second case resulted in the same maximum vMS. However, the vMS distribution along the needle was different, which presented higher vMS value along the needle. For the third case, the highest vMS value was spotted at the center of the introducer hub. The vMS value distributions were visualized in Figure 3 . The transparency feature was used to show the inner hub surface in contact with the needle.

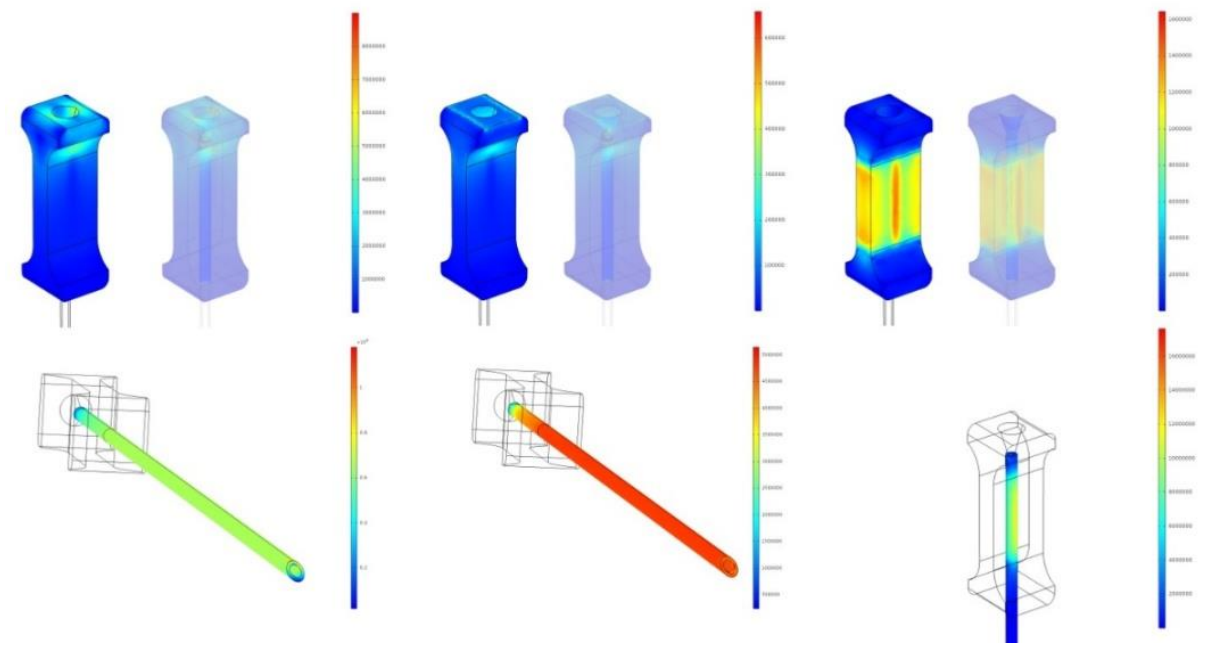

(a)

(b)

Figure 3 Von Mises stress (vMS) distribution on the introducer model in the first case to the third case (left to right): needle part (a), and hub part and transparency view (b)

The material differences influenced the resulted vMS values of the introducer model. The difference was more profound in the hub part because four different polymers were used: PS, PC, PP, and PE. For the first case, PE- and PS-hub introducers resulted in the highest and the lowest vMS values: $12.06 \mathrm{MPa}$ and PS (10.82 MPa), respectively. Likewise, for the second case, PE and PS resulted in the highest and the lowest values: $0.88 \mathrm{MPa}$ and $0.76 \mathrm{MPa}$, respectively. For the third case, the highest and the lowest vMS values were resulted by PP (4.77 $\mathrm{MPa}$ ) and PE (4.57 MPa). The bar chart of the vMS values from each hub material and case were presented in Figure 4.

The mechanical integrity of the introducer model was evaluated by comparing the vMS values with the tensile strength of the material. All the maximum vMS values for each material and test case were lower than the tensile strength of the respected material. The results showed that the introducer model would not encounter material failure in all assigned cases. Furthermore, the ratio of vMS:TS was calculated using Eq. 6 to obtain the MTR value for each case and material. Accordingly, TMR was assigned as one of the properties in WPM, along with the other properties:prices, CRD, hardness, WA, and IPA resistance (presented in Table 3). Using the DL method, the important value for each property was calculated. MTR values, despite the case, were placed in the top three because the properties were the most crucial aspect for material consideration. 


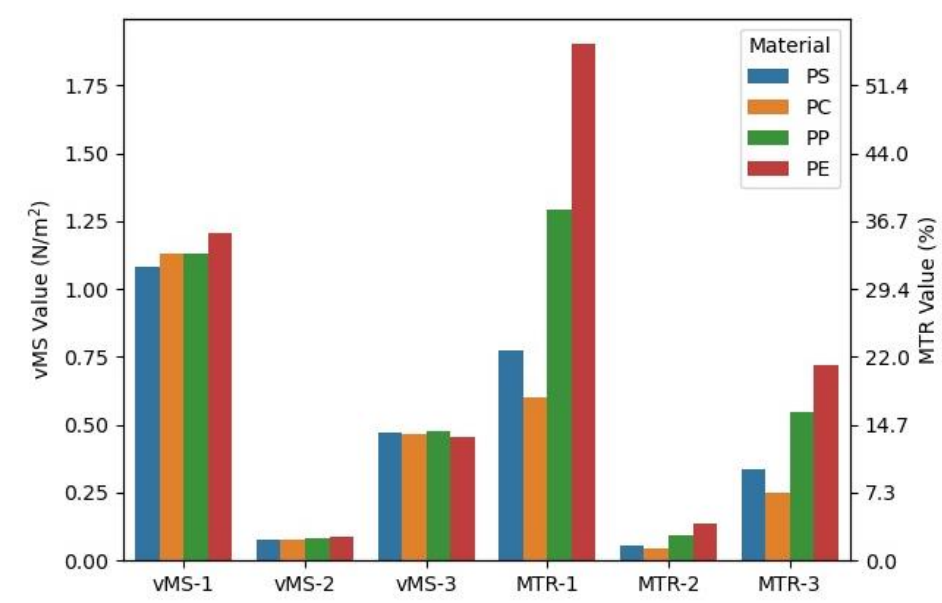

Figure 4 Bar chart of the maximum vMS and MTR of each polymer candidate and case at the hub part

The MTR ranking considered the frequency of the stress applied to the material and subsequently the value of MTR. MTR-1 values are mostly the highest among the other MTR values, but the tendency of an introducer to accidentally fall is low. Meanwhile, forces applied to the grip are considerably more frequent. The grip force can even be higher when the surgeon wants to be more focused during the needle navigation. On the other hand, MTR-2 values are the lowest. Therefore, MTR-1 was placed below MTR-3 in the importance of properties and followed by MTR-2.The $4^{\text {th }}$ property was the price since the introducer is designed to be disposable (Tsen and Hepner, 2006; Erskine, 2008). Disposable medical devices tend to attract users with a cheap price when the quality is on par. Moreover, since the introducer is disposable, CDR is not highly necessary. The sterilization, which presumably uses gamma irradiation, might take one cycle before the packaging in the manufacturing plant. In order, the rank went on hardness, WA, and IPA resistance. The important values of properties are presented in Table 2.

The summarized comparison of each material is presented in Table 3. Based on each performance index of materials, PC received the highest score (84.23), while PE received the lowest (42.94). Using WPM, PC is the most recommended polymer to use as the hub of a spinal stem cell introducer.

\section{Conclusions}

As the early step of material selection, FEM was successfully performed to compare four polymers: PS, PC, PP, and PE as candidates for hub materials of a spinal stem cell introducer. The result proved that the introducers made of AISI SS304 with PC-, PE-, PP-, and PS-hub are mechanically strong to survive the equivalent forces of accidental fall and grip of surgeons. The translated vMS, MTR, was categorized into three values, following the three separate cases, and used as the three most important properties in WPM. The properties following the three MTR values were prices, CDR, hardness, WA, and IPA resistance. WPM results indicated that $\mathrm{PC}$ received the highest score, thus recommended as a hub material.

\section{Acknowledgment}

This research was supported by the Universitas Indonesia PUTI Grant 2020 from Universitas Indonesia with Contract Number: NKB-888/UN2.RST/HKP.05.00/2020. 
Table 2 Determination of relative importance of properties (P) using digital logic (DL) method

\begin{tabular}{|c|c|c|c|c|c|c|c|c|c|c|c|c|c|c|c|c|c|c|c|c|c|c|c|c|c|c|c|c|c|c|}
\hline & \multicolumn{28}{|c|}{ Number of possible decisions $[N=n(n-1) / 2]$} & \multirow[b]{2}{*}{$m$} & \multirow{2}{*}{ a } \\
\hline & 1 & 2 & 3 & 4 & 5 & 6 & 7 & 8 & 9 & 10 & 11 & 12 & 13 & 14 & 15 & 16 & 17 & 18 & 19 & 20 & 21 & 22 & 23 & 24 & 25 & 26 & 27 & 28 & & \\
\hline $\mathrm{P} 1$ & 1 & 1 & 1 & 1 & 1 & 1 & 1 & & & & & & & & & & & & & & & & & & & & & & 7 & 0.25 \\
\hline P2 & 0 & & & & & & & 1 & 1 & 1 & 1 & 1 & 1 & & & & & & & & & & & & & & & & 6 & 0.21 \\
\hline P3 & & 0 & & & & & & 0 & & & & & & 1 & 1 & 1 & 1 & 1 & & & & & & & & & & & 5 & 0.18 \\
\hline P4 & & & 0 & & & & & & 0 & & & & & 0 & & & & & 0 & 0 & 0 & 1 & & & & & & & 1 & 0.04 \\
\hline P5 & & & & 0 & & & & & & 0 & & & & & 0 & & & & 1 & & & & 0 & 1 & 1 & & & & 3 & 0.11 \\
\hline P6 & & & & & 0 & & & & & & 0 & & & & & 0 & & & & 1 & & & 1 & & & 1 & 1 & & 4 & 0.14 \\
\hline P7 & & & & & & 0 & & & & & & 0 & & & & & 0 & & & & 1 & & & 0 & & 0 & & 0 & 1 & 0.04 \\
\hline P8 & & & & & & & 0 & & & & & & 0 & & & & & 0 & & & & 0 & & & 0 & & 0 & 1 & 1 & 0.04 \\
\hline & & & & & & & & & & & & & & & & $\mathrm{SU}$ & & & & & & & & & & & & & 28 & 1.00 \\
\hline
\end{tabular}

Table 3 The compartment of each hub material in several properties (Foster Corporation, 2020; K-mac Plastics, 2020; MatWeb, 2020; Raw Materials \& Prices, 2020), performance index and ranking of material

\begin{tabular}{|c|c|c|c|c|c|c|c|c|c|c|c|}
\hline \multirow[b]{2}{*}{ Material } & \multirow[b]{2}{*}{$\mathrm{P}$ and $\beta$} & 1 & 2 & 3 & 4 & 5 & 6 & 7 & 8 & \multirow[b]{2}{*}{$\gamma$} & \multirow[b]{2}{*}{ Rank } \\
\hline & & $\begin{array}{c}\text { MTR-3 } \\
(\%)\end{array}$ & $\begin{array}{c}\text { MTR-1 } \\
(\%)\end{array}$ & $\begin{array}{c}\text { MTR-2 } \\
(\%)\end{array}$ & Hardness & $\begin{array}{c}\text { CDR } \\
(\mathrm{kGy})\end{array}$ & $\begin{array}{l}\text { Price } \\
(€ / \mathrm{kg})\end{array}$ & WA $(\%)$ & $\begin{array}{c}\text { IPA } \\
\text { Resistance }\end{array}$ & & \\
\hline \multirow{2}{*}{ PS } & $\mathrm{P}$ & $22.64 \%$ & $1.58 \%$ & $9.83 \%$ & 99.2 & 600 & 0.54 & 0.2020 & 3 & \multirow{2}{*}{81.16} & \multirow{2}{*}{2} \\
\hline & $\beta$ & 78.06 & 78.47 & 73.95 & 83.36 & 100.00 & 98.15 & 9.65 & 100.00 & & \\
\hline \multirow{2}{*}{ PC } & $\mathrm{P}$ & $17.67 \%$ & $1.24 \%$ & $7.27 \%$ & 119.0 & 250 & 0.82 & 0.2380 & 2 & \multirow{2}{*}{84.23} & \multirow{2}{*}{1} \\
\hline & $\beta$ & 100.00 & 100.00 & 100.00 & 100.00 & 41.67 & 64.63 & 8.19 & 66.67 & & \\
\hline \multirow{2}{*}{ PP } & $\mathrm{P}$ & $37.89 \%$ & $2.74 \%$ & $15.99 \%$ & 94.7 & 10 & 0.48 & 0.0721 & 3 & \multirow{2}{*}{52.81} & \multirow{2}{*}{3} \\
\hline & $\beta$ & 46.64 & 45.28 & 45.47 & 79.58 & 1.67 & 110.42 & 27.05 & 100.00 & & \\
\hline \multirow{2}{*}{ PE } & $P$ & $55.84 \%$ & $4.03 \%$ & $21.14 \%$ & 48.7 & 100 & 0.53 & 0.0195 & 1 & \multirow{2}{*}{42.94} & \multirow{2}{*}{4} \\
\hline & $\beta$ & 31.65 & 30.74 & 34.40 & 40.92 & 16.67 & 100.00 & 100.00 & 33.33 & & \\
\hline
\end{tabular}




\section{References}

Bakar Sulong, A., Arifin, A., Harun, Z., 2016. Jig Prototype for Computer-Assisted Total Knee Replacement and Its Flow Simulation. International Journal of Technology, Volume 7(1), pp. $132-140$

Black, E., Owens, K., Staub, R., Li, J., Mills, K., Valenstein, J., Hilgren, J., 2017. Evaluation of AISI Type 304 Stainless Steel as a Suitable Surface Material for Evaluating the Efficacy of Peracetic Acid-based Disinfectants against Clostridium Difficile Spores. PLOS One, Volume 12(10), pp. 1-10

Derby, R., Wolfer, L.R., Landers, M.H., 2016. Diskography. In: Advanced Concepts in Lumbar Degenerative Disk Disease, Pinheiro-Franco, J.L., Vaccaro, A.R., Benzel, E.C., and Mayer, H.M., (eds.), Springer, Berlin Heidelberg, Germany, pp. 109-135

Donnelly, E.M., Lamanna, J., Boulis, N.M., 2012. Stem Cell Therapy for the Spinal Cord. Stem Cell Research \& Therapy, Volume 3(24), pp. 1-9

Erskine, R.J., 2008. Assessment of a New Disposable Introducer for Spinal Needles. Anaesthesia, Volume 63(11), pp. 1238-1240

Faiz, J.M., Shayfull, Z., Nasir, S.M., Fathullah, M., Rashidi, M.M., 2017. Optimisation of Process Parameters on Thin Shell Part using Response Surface Methodology (RSM). AIP Conference Proceedings, Volume 1885(1), p. 020071

Farag, M.M., 2013. Materials Selection Process. In: Materials and Process Selection for Engineering Design, CRC Press, Third, Boca Raton, Florida, USA, pp. 291-340

Foster Corporation, 2020. Sterilization \& Chemical Resistance of Healthcare Polymers, Foster Corporation. Available Online at: https://www.fostercomp.com/, Accessed on October 24, 2020

Geiger, S., Hirsch, D., Hermann, F.G., 2017. Cell Therapy for Lung Disease. European Respiratory Review, Volume 26(144), pp. 1-7

Jujur, I.N., Sah, J., Bakri, A., Hadi, S., Wargadipura, A., 2015. Analysis of Oxide Inclusions on Medical Grade 316L Stainless Steel using Local Raw. International Journal of Technology, Volume 6(7), pp. 1184-1190

Jushiddi, M.G., Mulvihill, J.J.E., Chovan, D., Mani, A., Shanahan, C., Silien, C., Md Tofail, S.A., Tiernan, P., 2019. Simulation of Biopsy Bevel-Tipped Needle Insertion into Soft-Gel. Computers in Biology and Medicine, Volume 111, 103337

Khalajmasoumi, M., Koloor, S.S.R., Arefnia, A., Ibrahim, I.S., Yatim, J.M., 2012. Hyperelastic Analysis of High Density Polyethylene under Monotonic Compressive Load. Applied Mechanics and Materials, Volumes 229-231, pp. 309-313

K-mac Plastics, 2020. Chemical Resistance Chart for Various Plastic Materials, K-mac Plastics. Available Online at http://kmac-plastics.net/data/chemical/chemical.htm, Accessed on October 24, 2020

Lingadurai, K., Nagasivamuni, B., Muthu Kamatchi, M., Palavesam, J., 2012. Selection of Wire Electrical Discharge Machining Process Parameters on Stainless Steel AISI Grade-304 using Design of Experiments Approach. Journal of The Institution of Engineers (India): Series $C$, Volume 93(2), pp. 163-170

MatWeb, 2020. Online Materials Information Resource - MatWeb. Available Online at http://www.matweb.com/index.aspx, Accessed on July 25, 2020

Mcwha, K.J., 1998. Combined Spinal Epidural Needle Set. Available Online at https://patents.google.com/patent/EP0872215A2/en, Accessed on July 25, 2020

Menasché, P., Vanneaux, V., Hagège, A., Bel, A., Cholley, B., Cacciapuoti, I., Parouchev, A., Benhamouda, N., Tachdjian, G., Tosca, L., Trouvin, J.H., Fabreguettes, J.R., Bellamy, V., Guillemain, R., Suberbielle Boissel, C., Tartour, E., Desnos, M., Larghero, J., 2015. Human 
Embryonic Stem Cell-Derived Cardiac Progenitors for Severe Heart Failure Treatment: First Clinical Case Report. European Heart Journal, Volume 36(30), pp. 2011-2017

Raw Materials \& Prices, 2020. Plasticker. Available Online at https://plasticker.de/preise/pms_en.php?show=ok\&make=ok\&aog=A\&kat=Mahlgut, Accessed on July 25, 2020

Saini, M., Singh, Y., Arora, P., Aora, V., Jain, K., 2015. Implant Biomaterials: A Comprehensive Review. World Journal of Clinical Cases, Volume 3(1), pp. 52-57

Sallé, D., Cepolina, F., Bidaud, P., 2004. Surgery Grippers for Minimally Invasive Heart Surgery. In: IEEE International Conference on Intelligent Manipulation and Grasping (IMG), Italy, pp. 1-2

Schroeder, J., Kueper, J., Leon, K., Liebergall, M., 2015. Stem Cells for Spine Surgery. World Journal of Stem Cells, Volume 7(1), pp. 186-194

Silvestro, S., Bramanti, P., Trubiani, O., Mazzon, E., 2020. Stem Cells Therapy for Spinal Cord Injury: An Overview of Clinical Trials. International Journal of Molecular Sciences, Volume 21(2), pp. 1-26

Thomas, S.P., Thomas, S., Abraham, R., Bandyopadhyay, S., 2008. Polystyrene/Calcium Phosphate Nanocomposites: Contact Angle Studies based on Water and Methylene Iodide, Express Polymer Letters, Volume 2(7), pp. 528-538

Tsen, L.C., Hepner, D.L., 2006. Needles Used for Spinal Anesthesia. Expert Review of Medical Devices, Volume 3(4), pp. 499-508

Yang, J., Silvestro, C., Khatri, D., De Nardo, L., Daraio, C., 2011. Interaction of Highly Nonlinear Solitary Waves with Linear Elastic Media. Physical Review E, Volume 83(4), pp. 1-12 